\title{
A validated LC-ESI-MS/MS method for the quantification of Selegiline HCl in bulk and pharmaceutical formulation
}

\author{
R. Sangamithra, Krishna Veni Nagappan*, Sailaja Mukkamala, Anoop Karthika, S. T. Narenderan, Kowmudi Gullapalli \\ Department of Pharmaceutical Analysis, JSS College of Pharmacy, [A Constituent College_-JSS Academy of Higher Education \& Research], Ooty, The Nilgiris, \\ Tamilnadu, India.
}

\begin{tabular}{l}
\hline ARTICLE INFO \\
\hline Received on: 10/12/2018 \\
Accepted on: 08/05/2019 \\
Available online: 01/07/2019 \\
\hline Key words: \\
LC-MS/MS, MRM, \\
Parkinson's disease, \\
Selegiline HCl, validation.
\end{tabular}

\begin{abstract}
Selegiline $\mathrm{HCl}$ is an irreversible MAO-B inhibitor used to reduce symptoms in early-stage Parkinson's disease. It is used as an adjunct to drugs, such as L Dopamine (L-DOPA). The present study is designed to develop and validate a rapid, sensitive, and straightforward separation method with Electrospray ionization and triple quadrupole mass analyzer for the quantification of Selegiline $\mathrm{HCl}$ in bulk and pharmaceutical formulation. Zorbax $\mathrm{C}_{18}$ column $(50 \mathrm{~mm}$ $\times 4.6 \mathrm{~mm}$ i.d, $5 \mu$ particle size) was used for the separation of analyte and internal standard. The samples were eluted using $0.1 \%$ Formic acid in water and Methanol $(40: 60 \% \mathrm{v} / \mathrm{v})$ which is delivered at $0.5 \mathrm{ml} / \mathrm{minute}$ flow rate, with a chromatographic runtime of 5 minutes. The eluents were monitored using a tandem mass spectrometer equipped with an electrospray ionization in positive mode and a triple quadrupole mass analyzer. The detection was carried out in multiple reaction-monitoring mode by quantifying the $\mathrm{m} / \mathrm{z} 188.05 \rightarrow 91.10$ ion transition pair; with collision energy $-29.0 \mathrm{~V}$ for Selegiline $\mathrm{HCl}$. Linearity was achieved over the concentration range $3.5-6.5 \mathrm{ng} / \mathrm{ml}$ for the developed method. The limit of detection and limit of quantification were found to be 0.2 and $0.5 \mathrm{ng} / \mathrm{ml}$, respectively. The correlation coefficient $\left(r^{2}\right)$ value was $\geq 0.9985$ for Selegiline $\mathrm{HCl}$. This method offers a sensitive quantification of Selegiline $\mathrm{HCl}$ in the pharmaceutical formulation.
\end{abstract}

\section{INTRODUCTION}

Selegiline $\mathrm{HCl}$ is an irreversible MAO-B inhibitor used to reduce symptoms in early-stage Parkinson's disease (Magyar, 2011).

Enhancing the superoxide dismutase and catalase activity in the striatum are the multiple dose effects discrete to Monoamine oxidase inhibitors (MAO) inhibition, which stimulates the nigrostriatal dopaminergic neurons and averts agelinked morphological changes in the neurocytes located in the substantia nigra (Knoll, 1992). It is most often used as an adjunct to drugs, such as L Dopamine (L-DOPA) although it has been used off-label as a solo treatment. MAO inhibition by Selegiline to an active moiety facilitates the irretrievable combination with the

"Corresponding Author

Krishna Veni Nagappan, Department of Pharmaceutical Analysis, JSS College of Pharmacy [A Constituent College-JSS Academy of Higher Education \& Research], Ooty, India.Email: krisath@jssuni.edu.in active site and the enzyme's FAD cofactor. Considering the fact that the selegiline has got a higher affinity for type B active site over type A active site, selective inhibition of MAO type B could be possible by administering selegiline at the recommended dose (Heinonen et al., 1994).

A thorough review of the literature was carried out to enumerate the reported analytical methods for the quantification of Selegiline HCl. Danafar (2016) had reported an HPLC-UV method for the quantification of selegiline in human plasma. Stability indicating Reverse Phase High Performance Liquid Chromatography coupled with Ultra Violet Detector (RP-HPLC-UV) method was developed and reported for the quantification of Selegiline $\mathrm{HCl}$ in the pharmaceutical formulation by Kalaskar and Nagras (2014). La Croix et al. (1994) had reported a rapid, robust, and selective HPLCFluorescence detection for the metabolite analysis in identifying three primary metabolites, viz., amphetamine (L-deprenyl), methamphetamine (MA), and norselegiline of selegiline in human plasma. Tzanavaras et al. (2008) had reported an optimized and validated HPLC-UV method for the quantification of Selegiline $\mathrm{HCl}$ in dissolution samples. Swift separation of the analyte from 
the sample matrix was accomplished within 60 seconds at $220 \mathrm{~nm}$. Katagi et al. (2001) had reported an HPLC-ESI-MS method for the metabolite analysis of selegiline metabolites, selegiline $\mathrm{N}$ oxide in particular, along with other metabolites in urine. The method can be used to discriminate selegiline users from MA users. Nishida et al. (2006) reported a sensitive HPLC-ESI-MS method by employing a novel derivatization technique for the simultaneous estimation of MA and amphetamine (AP) enantiomers, desmethylselegiline along with Selegiline in human hair. This method was successfully applied to long term methamphetamine abusers and selegiline users. Slawson et al. (2002) reported an HPLC-APCI-MS/MS method for the sensitive and specific detection of selegiline along with its metabolites in the sub-nanogram concentrations in human plasma. Metabolites of selegiline include N-DMSG, methamphetamine, and AP.

From the available literature, it is evident that a successful quantification of selegiline in pharmaceutical formulations, and metabolites of selegiline in biological samples has been made possible by the methods as mentioned earlier. By reviewing the available methods, this study is designed to develop a validated Liquid Chromatography - Electro Spray Ionisation-Mass Spectrometry/Mass Spectrometry (LC-ESI-MS/MS) method for a simple, precise, accurate, specific, and selective quantification of Selegiline $\mathrm{HCl}$ in bulk and pharmaceutical formulation.

\section{MATERIALS AND METHODS}

\section{Chemicals}

Dr. Ramalingam Peraman gifted Selegiline $\mathrm{HCl}$ reference standard. Methanol (LC-MS/MS grade) was purchased from Merck, (Mumbai, India). Formic acid (AR grade) was purchased from Qualigens fine chemicals (Mumbai, India). MilliQ-water for analysis was prepared using milli-Q-purification system (Millipore, Bedford).

\section{LC-MS/MS instrument and condition}

For LC-MS/MS analysis, an ultra-fast liquid chromatography (UFLC) system which was equipped with a solvent delivery system LC-20AD pump, a photo-diode array detector SPD-M20 PDA, a CTO-20AC column oven, a CBM20 alite controller, and a SIL-20AC autosampler. UFLC was coupled with a tandem quadrupole mass spectrometer (Shimadzu 8030, Tokyo, Japan) interfaced by electrospray ionization (ESI). Data acquisition was performed using LC solutions software. For the analysis, optimized parameters include desolvation Line temperature $250^{\circ} \mathrm{C}$, Block Temperature $200^{\circ} \mathrm{C}$, Detector voltage $1.3 \mathrm{kV}$, Nitrogen gas (Nebulizer gas) and drying gas were pumped at the rate of 1.5 and $151 /$ minute, respectively. Argon gas was used for collision-induced dissociation experiments $(230 \mathrm{kPa})$.

\section{Chromatographic conditions}

A zorbax $\mathrm{C}_{18}$ column $(50 \mathrm{~mm} \times 4.6 \mathrm{~mm}$ i.d, $5 \mu$ particle size) was selected as a stationary phase. The mobile phase composition of $0.1 \%$ Formic acid in water and Methanol (40:60 $\mathrm{v} / \mathrm{v}$ ) was pumped by maintaining a flow rate of $0.5 \mathrm{ml} /$ minute. Auto-injector injects $10 \mu \mathrm{l}$ volume of sample per injection into the system. The column temperature was set ambient. The total run time for this chromatographic separation was 5 minutes. The eluents were monitored using an ESI (positive ionization mode) interfaced triple quadrupole mass analyzer. The detection and quantification of Selegiline $\mathrm{HCl}$ were achieved under multiple reaction-monitoring $(\mathrm{MRM})$ mode at a retention time of 1.94 minutes. The precursor to product ion transitions and collision energies for Selegiline $\mathrm{HCl}$ were as follows: Selegiline $\mathrm{HCl} \mathrm{m/z}$ $188.15 \rightarrow 91.10 ;-29.0 \mathrm{~V}$.

\section{Preparation of calibration standards and quality control samples}

A primary stock solution of Selegiline $\mathrm{HCl}$ was prepared by dissolving $10 \mathrm{mg}$ of the standard in $10 \mathrm{ml}$ of methanol to obtain $1 \mathrm{mg} / \mathrm{ml}$ stock solution. Various working standards ranging from 3.5 to $6.5 \mathrm{ng} / \mathrm{ml}$ of Selegiline $\mathrm{HCl}$ was prepared in mobile phase methanol and $0.1 \%$ Formic acid $(60: 40 \% \mathrm{v} / \mathrm{v})$ and were used as calibration standards. Three different levels [Lower Quality Control (LQC), Middle Quality Control (MQC), and High Quality Control samples (HQC)] of quality control samples were similarly prepared at a concentration of $4 \mathrm{ng} / \mathrm{ml}$ (LQC), $5 \mathrm{ng} / \mathrm{ml}$ (MQC), and $6 \mathrm{ng} / \mathrm{ml}(\mathrm{HQC})$ in the mobile phase. These standards were stored at $-8^{\circ} \mathrm{C}$ until further analysis.

\section{Preparation of sample solution}

To assess the applicability of the developed LC-MS/MS method on real samples, 10 tablets of the marketed formulation were taken and crushed into a fine powder. Powder equivalent to 10 $\mathrm{mg}$ of Selegiline $\mathrm{HCl}$ was accurately weighed and transferred into a $100-\mathrm{ml}$ flask, and the analyte was successively extracted thrice with 20-ml methanol. The extracts were filtered, combined, and evaporated to dryness on a water bath at $60^{\circ} \mathrm{C}$. The dried residue was reconstituted with $10 \mathrm{ml}$ of LC-MS/MS grade methanol in a 10$\mathrm{ml}$ standard flask. This solution was suitably diluted with the mobile phase and analyzed by the optimized chromatographic conditions.

\section{Method validation}

The validation of the developed method was performed based on ICH Q2 (R1) (2005) guidelines for analytical method validation. The present LC-MS/MS method was validated for specificity, sensitivity, linearity and range, precision, accuracy, ruggedness, and robustness.

\section{Selectivity}

The selectivity of the method was performed to prove that the analyte response is not affected by the potential interferences and endogenous compounds co-eluting with Selegiline $\mathrm{HCl}$ in real samples. It was measured by comparing the chromatograms of the diluent with the corresponding LOQ calibration standard.

\section{Linearity}

Linearity for Selegiline $\mathrm{HCl}$ was performed using calibration standards ranging from 3.5 to $6.5 \mathrm{ng} / \mathrm{ml}$. The standards were injected in triplicate; the chromatograms were recorded under optimized chromatographic conditions. The calibration curve was constructed using the least squares method by plotting the peak area $v s$. the concentration of Selegiline $\mathrm{HCl}$.

\section{Precision and accuracy}

Six independent injections of Selegiline $\mathrm{HCl}$ were analyzed for intra-day and inter-day precision at three different 
concentration levels (LQC, MQC, and HQC) for Selegiline $\mathrm{HCl}$. The precision was recorded as a measure of $\% \mathrm{CV}$ in which the value does not exceed 2\% for nominal QC and 5\% for LQC.

The method's accuracy was expressed as recovery studies, performed by the standard addition method, by adding a known amount of drug to the actual sample and the chromatographic conditions optimized were used to perform the analysis. The recovery studies were performed at three QC levels. The \% mean recovery, $\mathrm{SD}$, and $\% \mathrm{CV}$ were calculated and reported.

\section{Limit of detection (LOD) and limit of quantification (LOQ)}

If a method detects very low concentration, the method is said to be sensitive. According to the ICH guidelines, based on peak height, signal-to-noise ratio $(\mathrm{S} / \mathrm{N}), \mathrm{LOD}$, and LOQ values were determined.

\section{Robustness and ruggedness}

The robustness of the developed method was determined by altering experimental conditions such as flow rate $( \pm 0.1 \mathrm{ml} /$ minute), $\mathrm{pH}( \pm 0.2)$, column oven temperature $\left( \pm 2^{\circ} \mathrm{C}\right)$, and the concentration of the organic phase $( \pm 2 \%)$ to assess the deviation from the optimized chromatographic condition.

\section{System suitability}

A vital part of the development and validation of an analytical method is the calculation of system suitability parameters as it ensures the ideal performance of the system. Chromatographic parameters, viz., Retention time $\left(R_{\mathrm{t}}\right)$, Theoretical Plates $(N)$, and Asymmetry Factor $(A)$ were monitored after six replicate analysis of standard Selegiline $\mathrm{HCl}$ at a concentration of $5 \mathrm{ng} / \mathrm{ml}$.

\section{RESULTS AND DISCUSSION}

\section{Method development and optimization of chromatographic conditions}

Various chromatographic conditions, including mobile phase composition and column type, were optimized for better resolution and sensitivity. Trials were carried out to achieve proper resolution. Improved detection, ionization, and recovery of the analyte with an ESI interface at positive ionization mode were observed with a mobile phase composed of Methanol and $0.1 \%$ formic acid. The suitability and robustness of the method were checked with several $\mathrm{C}_{18}$ and Cyano columns. The Zorbax $\mathrm{C}_{18}$ column ( $50 \mathrm{~mm} \times 4.6 \mathrm{~mm}$ i.d, $5 \mu$ particle size $)$ provided good selectivity, sensitivity, and symmetric peak shape for Selegiline $\mathrm{HCl}$. The MRM transitions were selected as $\mathrm{m} / \mathrm{z} 188.15 \rightarrow 91.10$; with a collision energy of $-29.0 \mathrm{~V}$. The MS spectra and standard MRM chromatograms for Selegiline $\mathrm{HCl}$ are shown in Figures 1 and $2 \mathrm{a}$ and $\mathrm{b}$.

The real goal of the validation process was to challenge the method and determine the limits of accepted variability for the conditions needed to run the method.

Linearity was demonstrated from 3.5 to $6.5 \mathrm{ng} / \mathrm{ml}$. The calibration curve includes six calibration standards. The analysis was carried out with three sets of standards on six different days. With a regression equation of $y=241,700 x-84896$, an average correlation coefficient of 0.9985 was obtained. The calibration standards and their respective peak area are depicted in Table 1, the calibration curve was shown in Figure 3.
The assay for the marketed formulations was carried out after extraction with methanol, evaporation to dryness, and reconstitution with a suitable solvent. The results are shown in

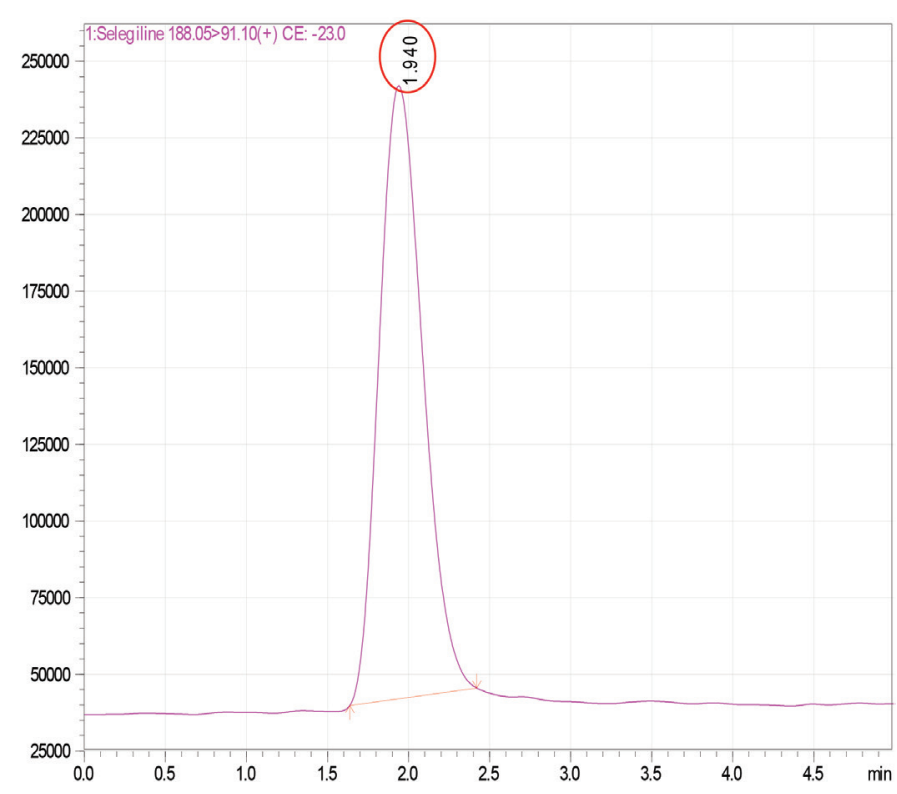

Figure 1. Typical MRM chromatogram of standard Selegiline $\mathrm{HCl}$ solution.
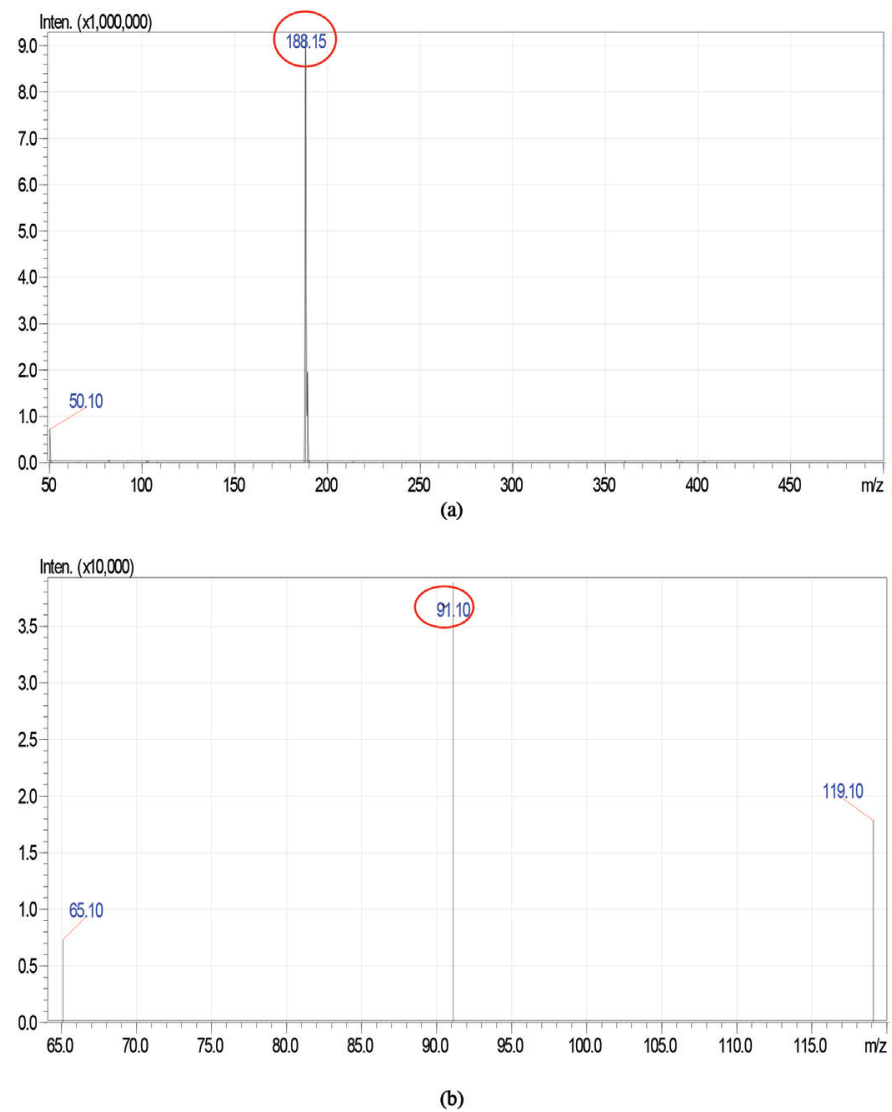

Figure 2. Typical (a) MRM scan spectra and (b) Product ion spectra of Selegiline $\mathrm{HCl}$ 
Table 1. Linearity and range for selegiline hydrochloride.

\begin{tabular}{cc}
\hline Concentration of Selegiline $\mathbf{H C l}(\mathbf{n g} / \mathbf{m l})$ & Peak Area* \\
\hline 3.5 & 772,544 \\
4.0 & 882,293 \\
4.5 & 992,474 \\
5.0 & $1,106,813$ \\
5.5 & $1,253,904$ \\
6.0 & $1,366,977$ \\
6.5 & $1,490,210$ \\
\hline
\end{tabular}

*Average of three determinations.

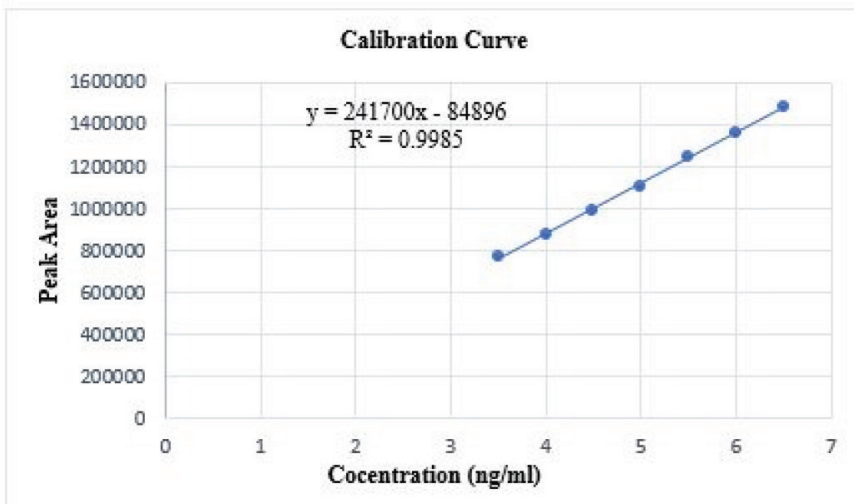

Figure 3. Calibration curve for Selegiline $\mathrm{HCl}$.

Table 2. Assay results of the marketed formulation of selegiline hydrochloride.

\begin{tabular}{lcc}
\hline Sample & Label claim & Amount present (mg/tablet) \pm SD; \%RSD \\
\hline Formulation $-\mathrm{I}$ & $10 \mathrm{mg}$ & $9.87 \pm 0.1205 ; 1.2206$ \\
\hline
\end{tabular}

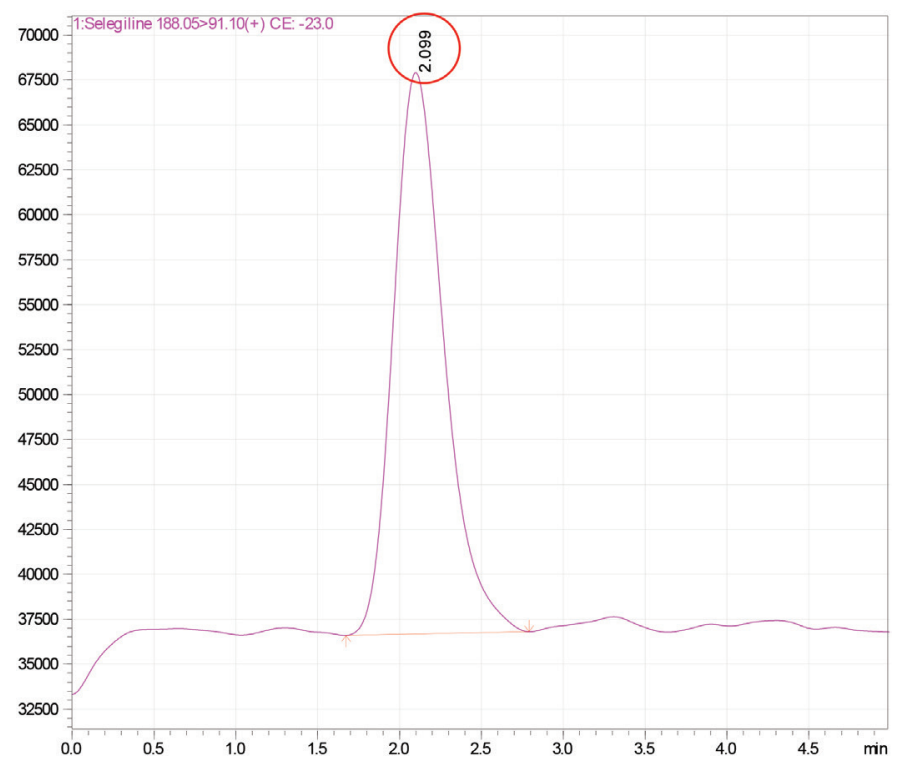

Figure 4. Typical TIC chromatograms of Selegiline $\mathrm{HCl}$ from pharmaceutical formulations.
Table 2. The chromatograms of Selegiline $\mathrm{HCl}$ from pharmaceutical formulations are shown in Figure 4.

Relative recovery experiments determined the accuracy of the optimized method. The percentage mean recovery value for Selegiline $\mathrm{HCl}$ was assessed at three QC levels (LQC, MQC, and HQC) and were found to be between $98.5 \pm 0.5 \%$ and the $\%$ relative standard deviation of the values was less than $5 \%$. Concerning the trials carried out and the description above, there was conclusive evidence that the developed method was accurate and reliable and results were given in Table 3.

The optimized method for the quantification of the Selegiline $\mathrm{HCl}$ was found to be precise which was evident from the values of coefficient of variation, which were in limits for all the concentrations $(\% \mathrm{RSD}-0.61-1.76)$. The results of the intraday and the inter-day precision studies were depicted in Table 4.

At the retention time of the selected drug candidate, there were no endogenous interferences. Based on these observations, the developed method of the assay is proved to be specific and selective.

The LOD and LOQ values of 0.2 and $0.5 \mathrm{ng} / \mathrm{ml}$ were determined based on peak height and signal-to-noise $(\mathrm{S} / \mathrm{N})$

Table 3. Accuracy studies of selegiline hydrochloride.

\begin{tabular}{ccc}
\hline $\begin{array}{c}\text { Actual } \\
\text { concentration(ng/ml) }\end{array}$ & $\begin{array}{c}\text { Recovered concentration } \\
(\mathbf{n g} / \mathbf{m l}) \pm \text { SD; \%RSD }(\boldsymbol{n}=\mathbf{3})\end{array}$ & $\begin{array}{c}\text { Percentage recovered } \\
(\mathbf{\%})\end{array}$ \\
\hline 4 & $3.87 \pm 0.0741 ; 1.9149$ & 96.75 \\
5 & $4.87 \pm 0.0702 ; 1.422$ & 97.40 \\
6 & $5.91 \pm 0.0661 ; 1.1190$ & 98.51 \\
\hline
\end{tabular}

Table 4. Precision studies for selegiline hydrochloride.

\begin{tabular}{ccc}
\hline $\begin{array}{c}\text { Actual } \\
\text { concentration(ng/ml) }\end{array}$ & $\begin{array}{c}\text { Intra-day calculated } \\
\text { concentration }(\boldsymbol{\mu g} / \mathbf{m l}) \pm \mathbf{S D} ; \\
\mathbf{\% R S D}(\boldsymbol{n}=\mathbf{6})\end{array}$ & $\begin{array}{c}\text { Inter-day calculated } \\
\text { concentration }(\mathbf{n g} / \mathbf{m l}) \pm \\
\mathbf{S D} ; \boldsymbol{\% R S D}(\boldsymbol{n}=\mathbf{6})\end{array}$ \\
\hline 4 & $3.91 \pm 0.0435 ; 1.1176$ & $3.86 \pm 0.0680 ; 1.7603$ \\
5 & $4.86 \pm 0.0850 ; 1.7475$ & $4.88 \pm 0.0351 ; 0.7186$ \\
6 & $5.91 \pm 0.0360 ; 0.6111$ & $5.86 \pm 0.0680 ; 1.1602$ \\
\hline
\end{tabular}

Table 5. Robustness studies of selegiline hydrochloride.

\begin{tabular}{cc}
\hline Parameters & Retention time \\
\hline Mobile phase ratio & $1.47 \pm 0.2$ \\
$59.5: 41.5$ & $1.81 \pm 0.2$ \\
$60: 40$ & $1.79 \pm 0.2$ \\
$61.5: 39.5$ & \\
pH of buffer & $1.9 \pm 0.2$ \\
2.6 & $1.81 \pm 0.2$ \\
2.7 & $1.76 \pm 0.2$ \\
2.8 & \\
Flow rate & $1.62 \pm 0.2$ \\
0.4 & $1.81 \pm 0.2$ \\
0.5 & $1.97 \pm 0.2$ \\
0.6 &
\end{tabular}


Table 6. System suitability parameters for selegiline hydrochloride.

\begin{tabular}{lc}
\hline Parameters & Selegiline $\mathbf{H C l}$ \\
\hline Linearity and range & $3.5-6.5 \mathrm{ng} / \mathrm{ml}$ \\
Regression equation & $y=241,700 x-84,896$ \\
Correlation coefficient & 0.9985 \\
Theoretical plates & 3433 \\
Asymmetric factor & 1.1 \\
Limit of Detection & $0.2 \mathrm{ng} / \mathrm{ml}$ \\
Limit of Quantification & $0.5 \mathrm{ng} / \mathrm{ml}$ \\
\hline
\end{tabular}

ratio. The robustness of the developed method was determined by varying experimental conditions such as flow rate $( \pm 0.1 \mathrm{ml} /$ minute), $\mathrm{pH}(0.2)$, column temperature $\left( \pm 2^{\circ} \mathrm{C}\right)$, organic phase concentration $( \pm 2 \%)$, and the changes have not much affected the peak area and retention time. The results are enumerated in Table 5.

The system suitability was monitored after six replicate analysis of standard Selegiline $\mathrm{HCl}$ at $\mathrm{MQC}$ and the parameters, viz., retention time $\left(R_{\mathrm{t}}\right)$, Peak Asymmetry Factor $(A)$, and Theoretical Plates $(N)$ were calculated and reported in Table 6. From the results, it was evident that the parameters are within the limits as specified by guidelines.

Anovel LC-MS/MS method was developed and validated which can be applied for the quantification of Selegiline $\mathrm{HCl}$ in a pharmaceutical formulation which offers excellent accuracy and significant advantages regarding high sensitivity (LOQ of $0.5 \mathrm{ng} / \mathrm{ml}$ ), short run-time (5.0 minute) in isocratic conditions. This method involves a simple sample preparation step and brief analysis, limited consumption of solvent, especially organic. The chromatograms show a well-resolved peak of Selegiline $\mathrm{HCl}$ without any interference.

\section{CONCLUSION}

A simple, specific, and accurate LC-MS/MS method was developed, validated, and successfully applied for the quantification of Selegiline $\mathrm{HCl}$. The developed method can be used in the analysis of quality control samples during manufacturing and also in BA/BE studies.

\section{ACKNOWLEDGMENTS}

The authors would like to thank the JSS Academy of Higher Education \& Research, Mysore for providing the facilities to carry the work.

\section{REFERENCES}

Danafar H. Simple and sensitive high-performance liquid chromatographic (HPLC) method for the determination of the selegiline in human plasma. Cognet Med, 2016; 3:1179244.
Heinonen EH, Anttila MI, Lammintausta RA. Pharmacokinetic aspects of L-deprenyl (selegiline) and its metabolites. Clin Pharmacol Ther, 1994; 56:742-9.

Kalaskar RC, Nagras MA. Stability Indicating RP-HPLC Method for Selegiline hydrochloride in pharmaceutical formulations. Asian J Pharm Res Dev, 2014; 2:5-13.

Katagi M, Tatsuno M, Miki A, Nishikawa M, Nakajima K, Tsuchihashi H. Simultaneous determination of selegiline-N-oxide, a new indicator for selegiline administration, and other metabolites in urine by high-performance liquid chromatography-electrospray ionization mass spectrometry. J Chromatogr B, 2001; 759:125-33.

Knoll J. The pharmacological profile of (-) deprenyl (Selegiline) and its relevance for humans: a personal view. Pharmacol Toxicol, 1992; 70:317-21

La Croix R, Pianezzola E, Strolin Benedetti M. Sensitive highperformance liquid chromatographic method for the determination of the three main metabolites of selegiline (L-deprenyl) in human plasma. J Chromatogr B, 1994; 656:251-8. $2011 ; 100: 65-84$

Magyar K. The pharmacology of selegiline. Int Rev Neurobiol,

Nishida $\mathrm{K}$, Itoh $\mathrm{S}$, Inoue $\mathrm{N}$, Kudo $\mathrm{K}$, Ikeda $\mathrm{N}$. Highperformance liquid chromatographic-mass spectrometric determination of methamphetamine and amphetamine enantiomers, desmethylselegiline and Selegiline in hair samples of long-term methamphetamine abusers or Selegiline users. J Anal Toxicol, 2006; 30:233-7.

Slawson MH, Taccogno JL, Foltz RL, Moody DE. Quantitative analysis of selegiline and three metabolites (N- desmethylselegiline, methamphetamine, and amphetamine) in human plasma by highperformance liquid chromatography- atmospheric pressure chemical ionization-tandem mass spectrometry. J Anal Toxicol, 2002; 26:430-7.

Tzanavaras PD, Themelis DG, Zotou A, Stratis J, Karlberg B. Optimization and validation of a dissolution test for selegiline hydrochloride tablets by a novel rapid HPLC assay using a monolithic stationary phase. J Pharm Biomed Anal, 2008; 46:670-5.

ICH Topic Q2 (R1). Validation of analytical procedure: text and methodology Q2(R1). In International Conference on Harmonisation of Technical Requirements for registration of Pharmaceuticals for human use, 2005.

How to cite this article:

Sangamithra R, Nagappan KV, Mukkamala S, Karthika A, Narenderan ST, Gullapalli K. A validated LC-ESI-MS/MS method for the quantification of selegiline hydrochloride in bulk and pharmaceutical formulation. J Appl Pharm Sci, 2019; 9(07):106-110. 